\title{
الإعلام التنموي ودوره في تفعيل التنمية المحلية
}

$$
\begin{aligned}
& \text { فطيمة لبصير } \\
& \text { كلية علوم الإعــلام و الاتصـال و السمعي ليصيل } \\
& \text { البصري } \\
& \text { جامعة صالح بوبنيدر - قسنطينة- 3- }
\end{aligned}
$$

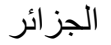

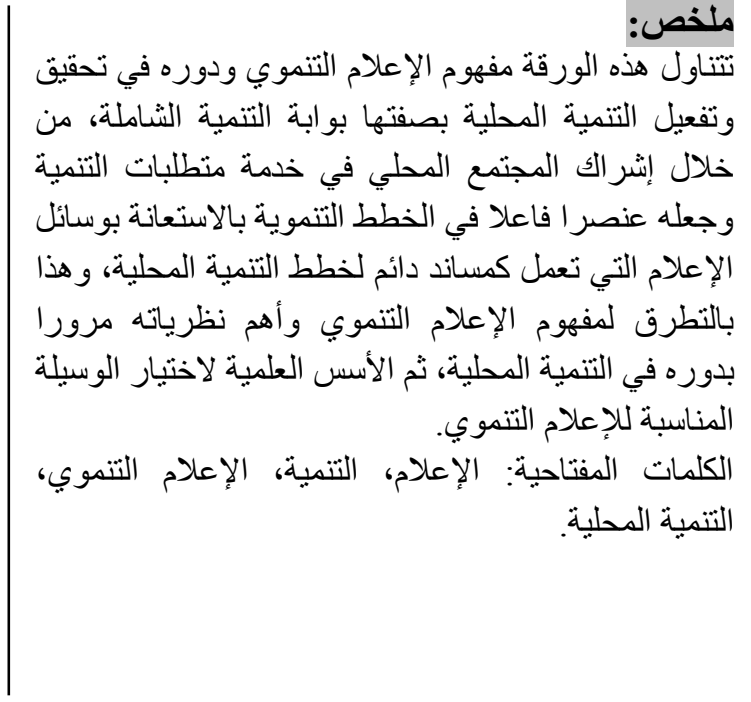

Abstract:

This paper examines the concept of media development and its role in achieving and activating local development as a gateway to global development, through the involvement of the local community in serving the requirements of development, and making it an active component in the developmental plans by the usage of media as a permanent proponent of local development plans, by tackling media development concept and its principal theories and its role in the local development, in addition to its scientific background in order to select the appropriate means of development media.

Keywords: Media, Development, Media Development, Local Development. 
وقد شكل موضوع التتمية المحلية أحد الركائز الأساسية التي تقوم عليها التتمية الثاملة، والتي

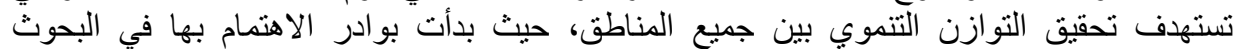

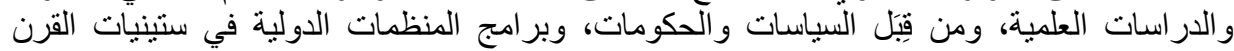

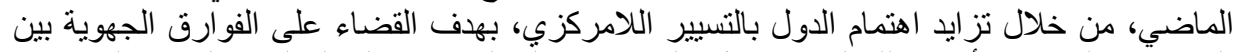

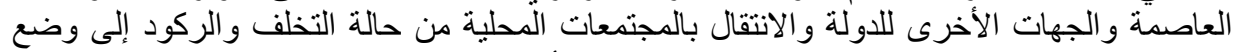

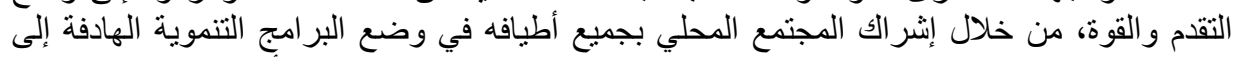

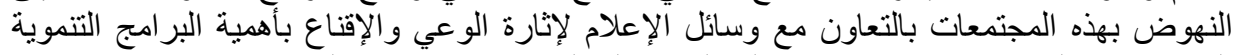

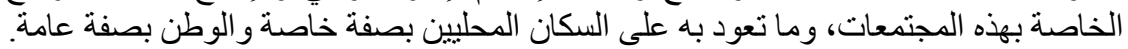

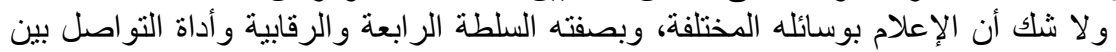

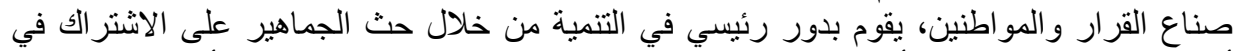

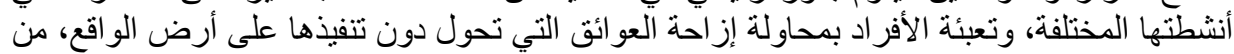

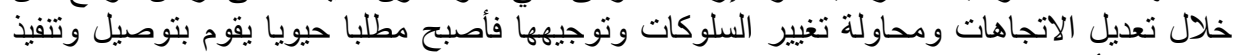

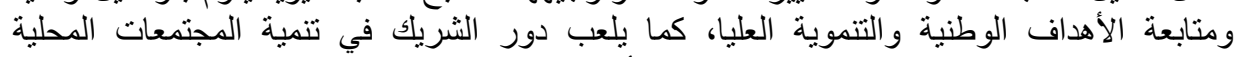

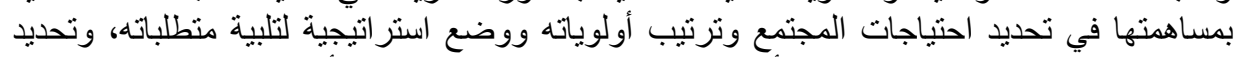

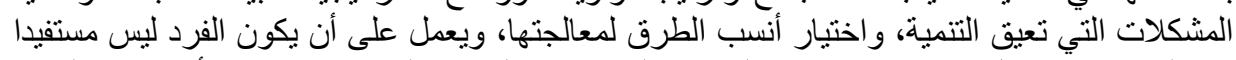

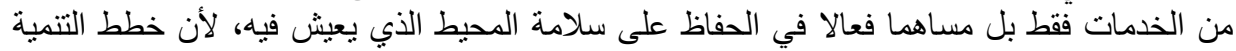

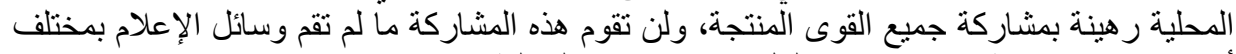

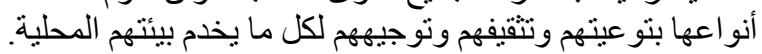

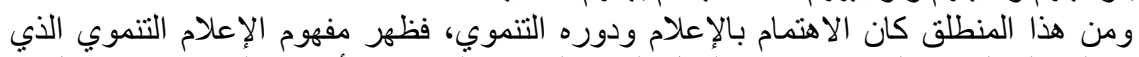

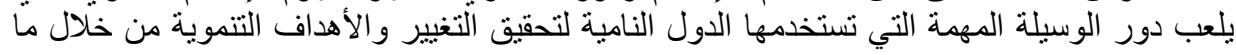

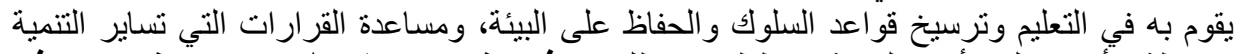

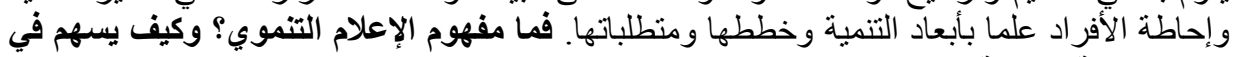

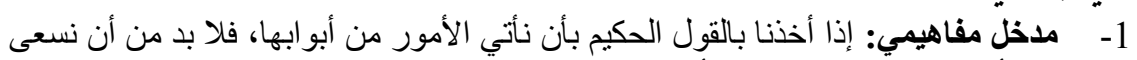

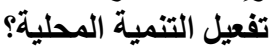

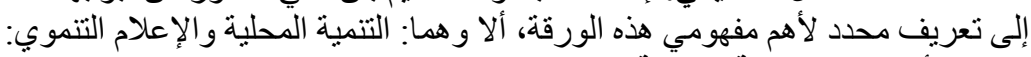
أ أـ مفهوم التنمية المحلية:

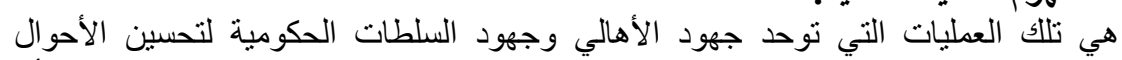

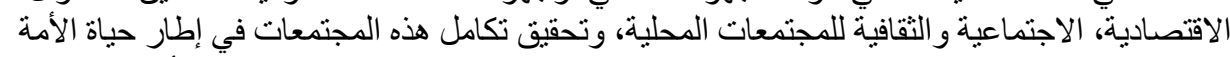

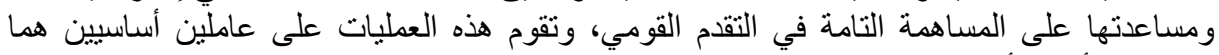

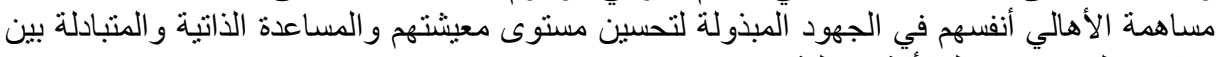

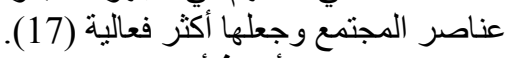

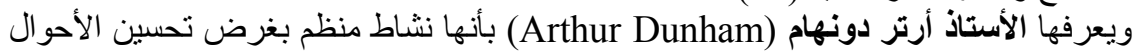

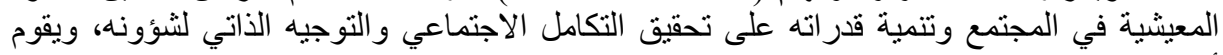

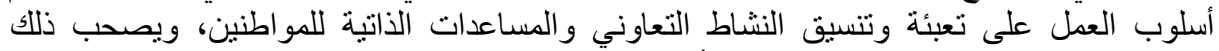

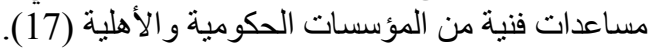

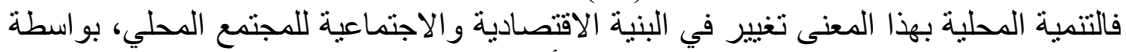

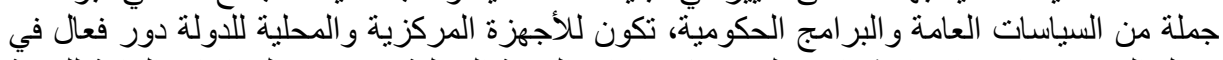

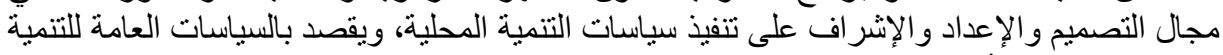

المحلية مجموعة الأهداف الملائمة لتحقيق التنمية الفعالة (1).

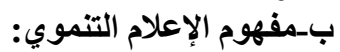

تعددت تسميات الإعلام التبنموي، فتارة يسمى (الصحافة المتخصصة في مواضيع التتمية)، وتارة (الإعلام للتنمية) وتارة أخرى (الإعلام لمساندة التنمية). 
وكيفما كانت التسمية فإنه يحمل معنى واحدا، تحدده نورا كبر ال (Nora Queberal) بقولها:

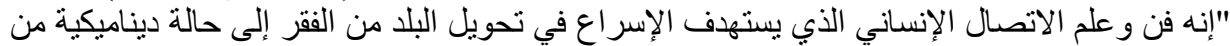

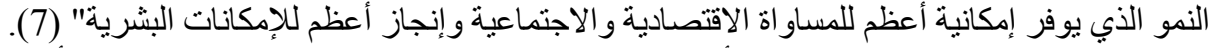

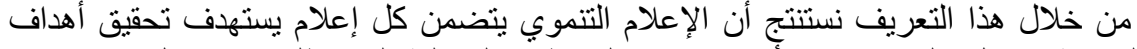

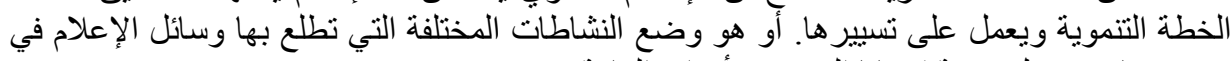
مجتمع ما في سبيل خدمة قضايا المجتمع و أهدافه العامة (11).

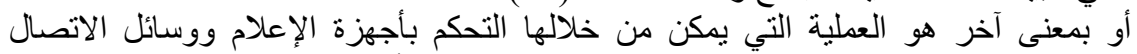

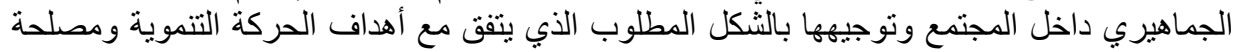

إذا فالإعلام التنموي هو استخدام وسائل الاتصال من إذاعة مسمو عة، وإذاعة مرئية (تلفزيون)

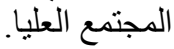

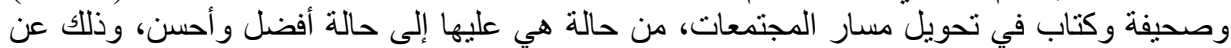

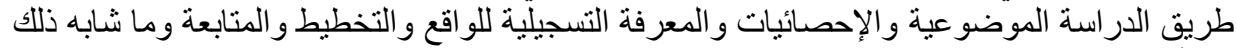
من أصول العلم، إضافة إلى المهارة المهنية والذاتية التي تتطلبها فنون الممارسة في العمل الإعلامي

2-

ينضوي تحت مظلة مصطلح الإعلام التتموي مجموعة من الأهداف، كما حددنها النشاطات العلمية التي تتاولت تأثير وسائل الإعلام في التجارب الإندام التنموية.

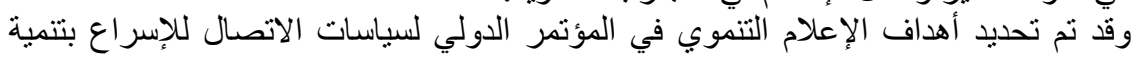
الاجتماعات الذي عقد سنة 1975، وذلك على ألنى النحو التالي:

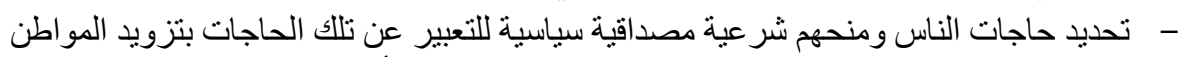
بمنفذ للنظام الاتصالي ليخدم كمرجع فعال للحكومة فئما فيما يتعلق بأهداف التنمية وخططها.

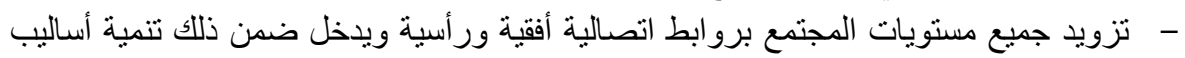

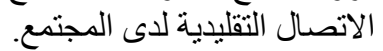
- - دعم الثقافة القيمة للمجتمعات المحلية عبر وسائل الإعلام الجماهيرية والمحلية التي تعتمد على لإنى التشجيع الفني للاعتر اف القومي بهذه الثقافة.

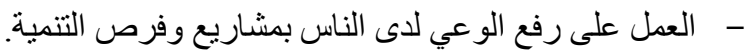

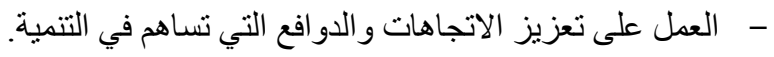

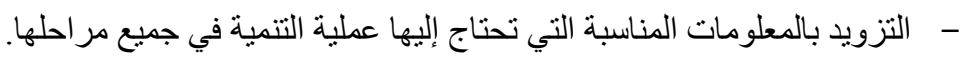

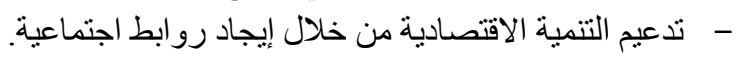
- - توفير الدعم لبعض المشاريع التتموية المحددة والخدمات الاجتماعية بما فيها الرعاية التماية الصحية، التنريب الزر اعي و المهني و المصلحة العامة، مشاريع تنظيم الأسرة (7).

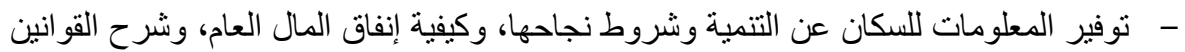

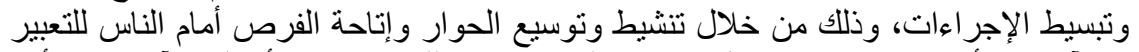
عن آر ائهم و أفكار هم بخصوص وذل من مشاريع الحكومة، وكذلك الاستماع لأقو الهم وآر ائهم و الأخذ

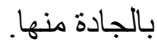
- اختيار المعلومات بشكل دقيق وجذاب واستخدام أساليب مشوقة من أجل جذب كل شرائح المجتمع للتفاعل مع الوسائل الإعلامية.

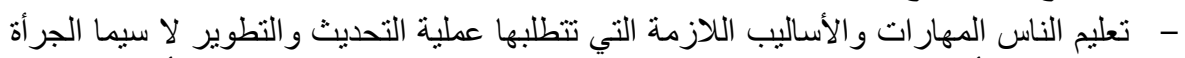

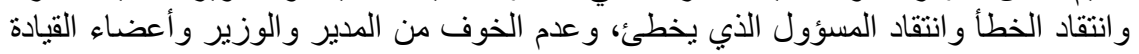




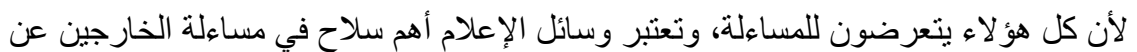

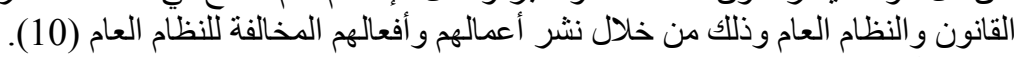
4- التظريات الإعلام التنموي:

انبتقت مجموعة من النظريات التي قدمها باحثون عالجت التبات دراساتهم علاقة الإعلام بالتتمية،

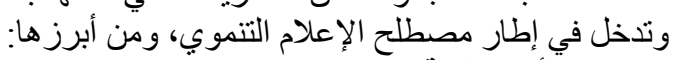

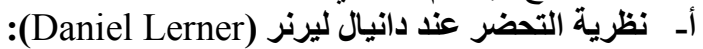
تعتبر نظرية ليرنر عن التحضر من أشهر النظرية النظريات الإعلامية في التنمية، وركزت على على دور

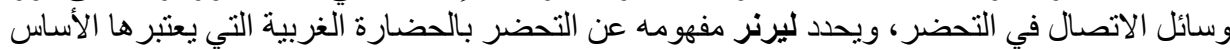

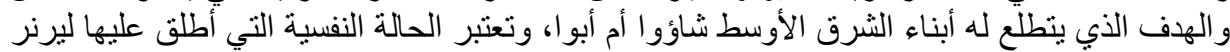

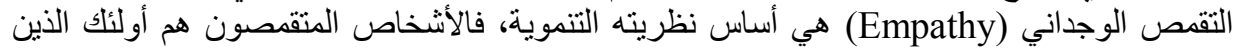

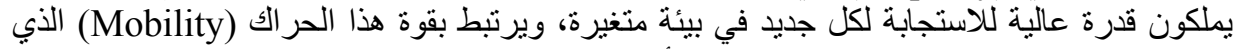

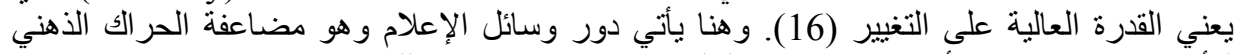

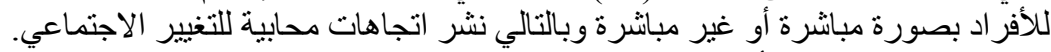

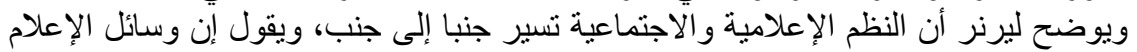

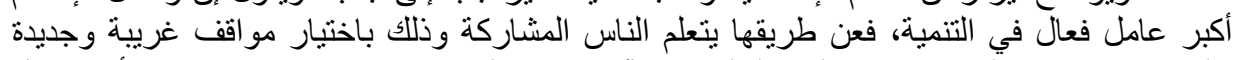

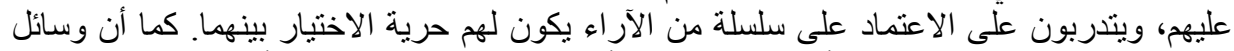

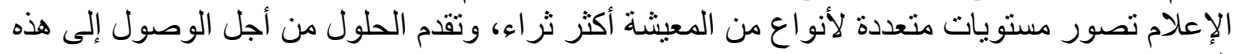

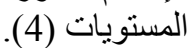

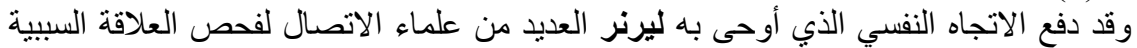

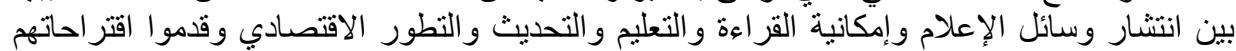

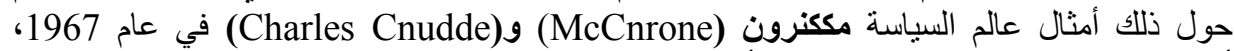

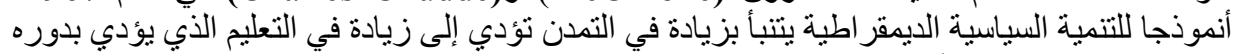

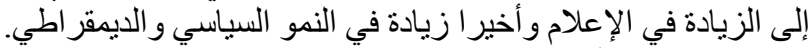

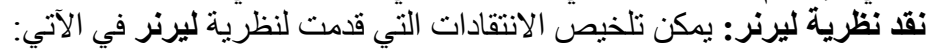

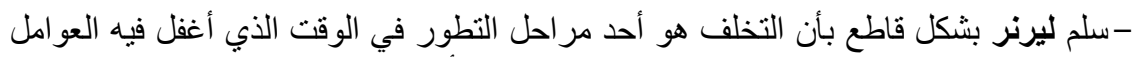

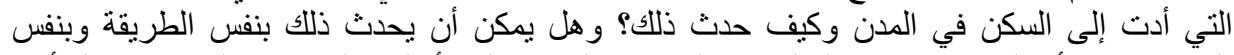

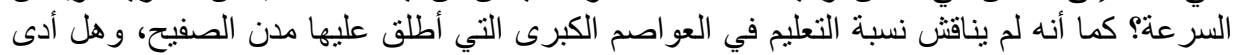

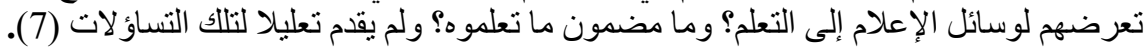

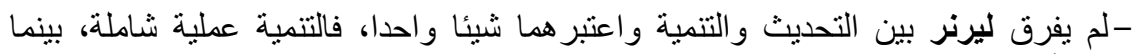
التحديث يمكن أن يكون المظهر المادي للتنمية.

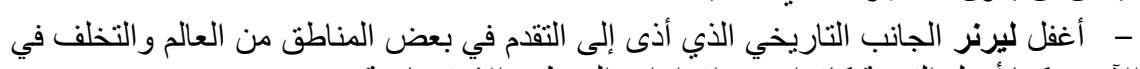

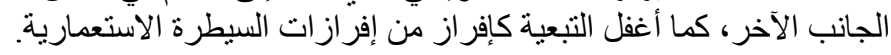

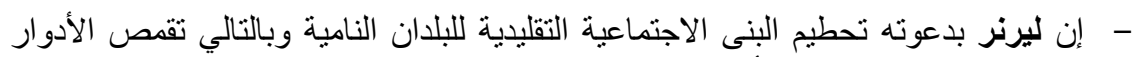

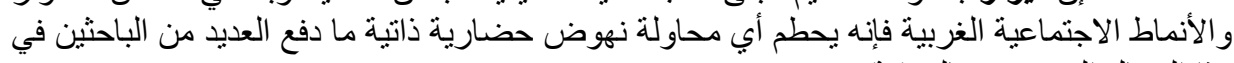
هذا المجال إلى وصفه بالعرقية.

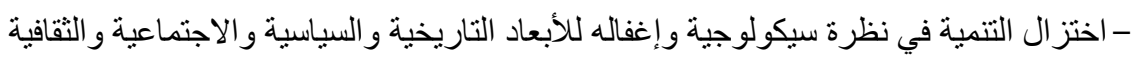

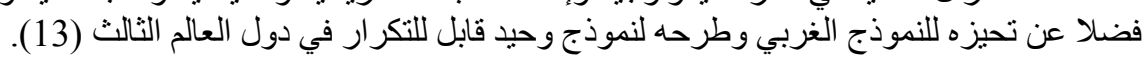

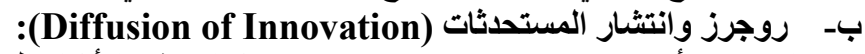

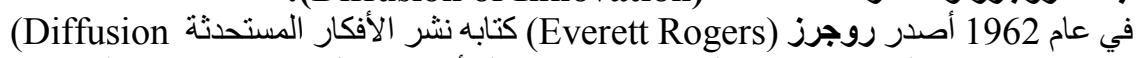
و of innovations) التطبيقية عن تقديم ونشر الأفكار الجديدة داعما بذللك ظهور نظرية عامة عن عن انتشار الأفكار المستحثثة 


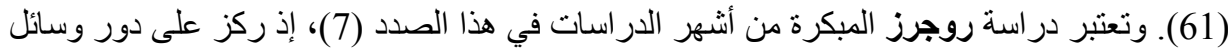

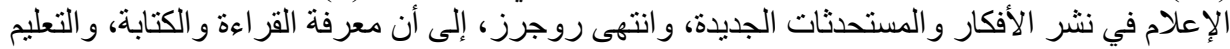

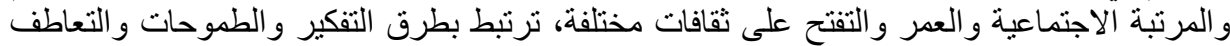

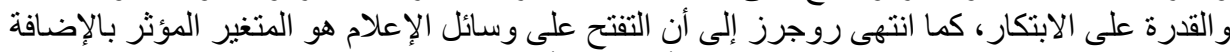

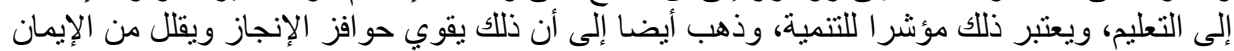

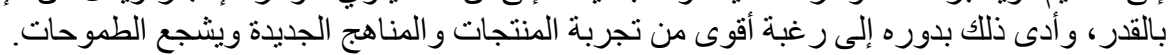

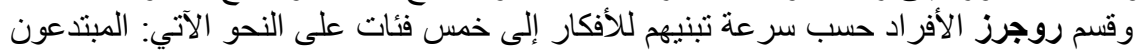

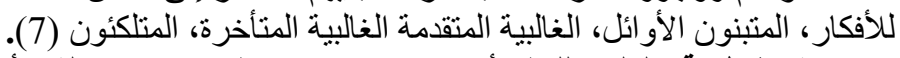

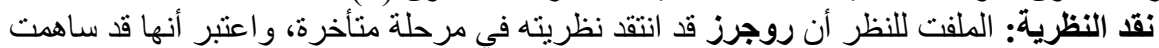

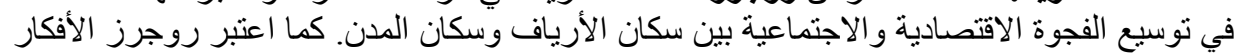

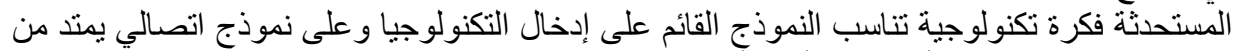

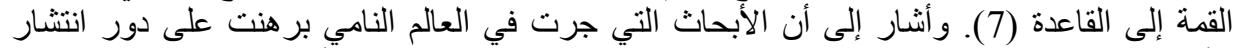

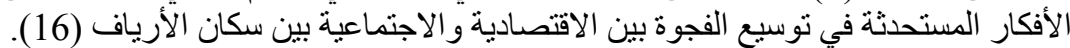

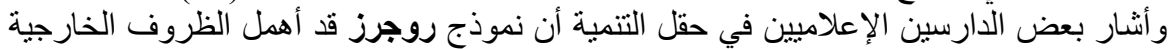

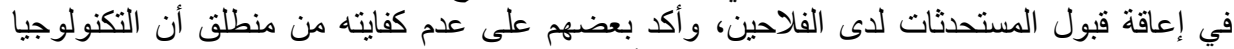

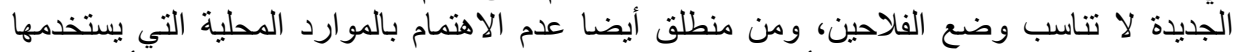

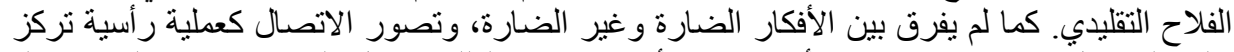

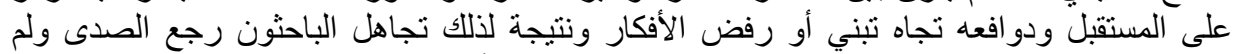

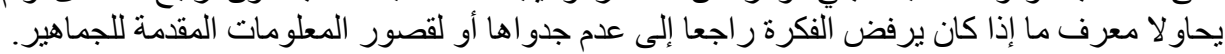

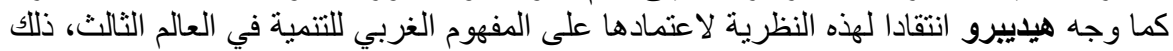

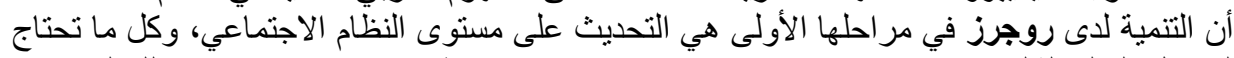

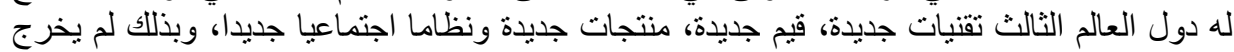

من عرقية ليرنر (7) - (7).

كما أهمل روجرز أيضا العلاقات الاقتصادية الدولية في القرن التاسع عشر وما اقترفته من تبعية

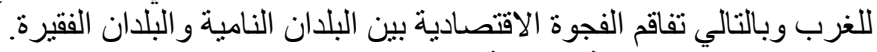
ج- شرام والتنمية الوطنية:

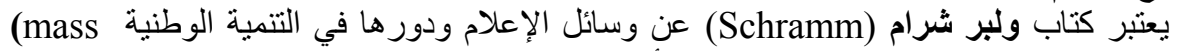
media and national development)

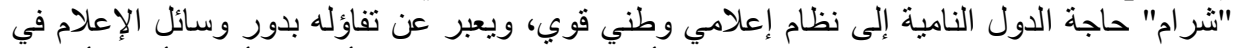

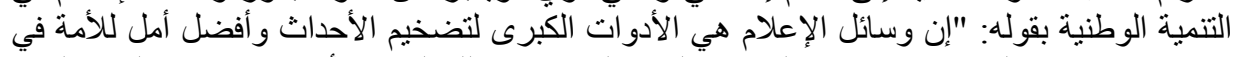

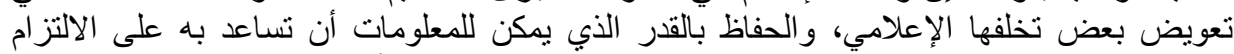

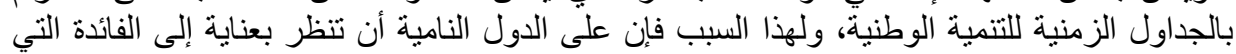

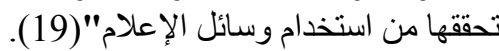

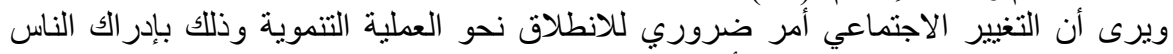

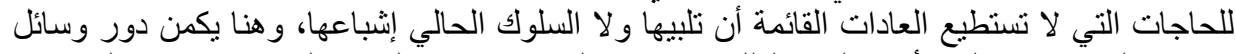

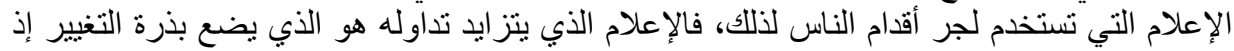

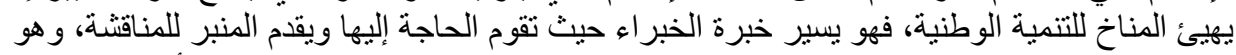

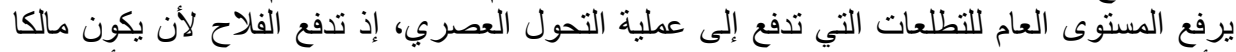

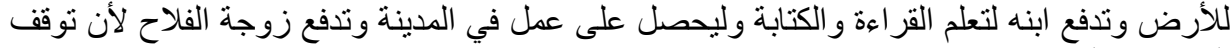

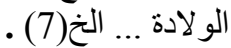

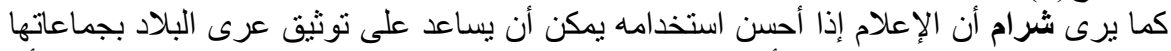

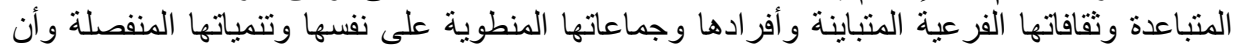


يجعل خطة التتمية خطة وطنية حقيقية (16)، ويقر أن وسائل الاتصال جماهيري تسنطيع أن تلعب دورا

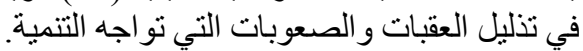

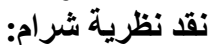

لا يختلف شرام عن غيره من علماء الاتصال الاجتماعي الغربيين، فقد سلك مسلكهم في اعتبار

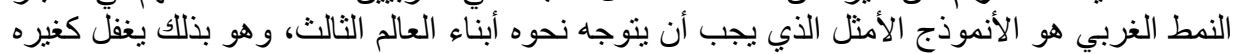

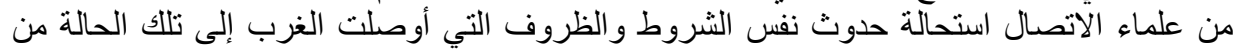
التطور التكنولوجي و المادي.

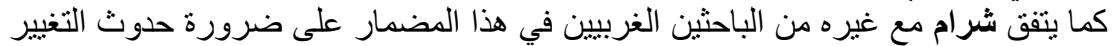

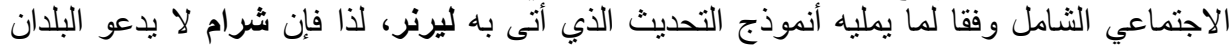

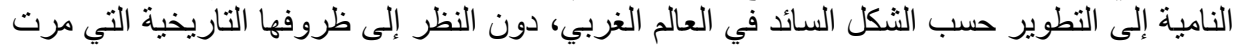

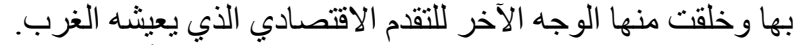

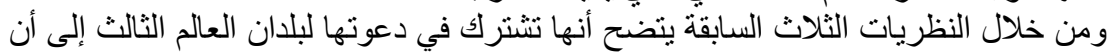

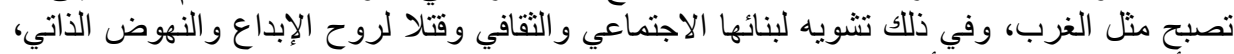

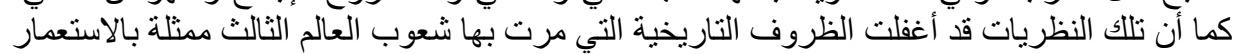

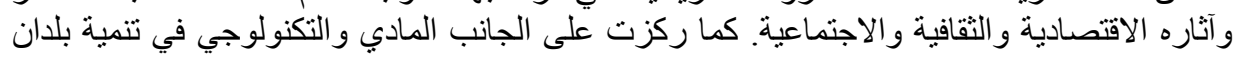

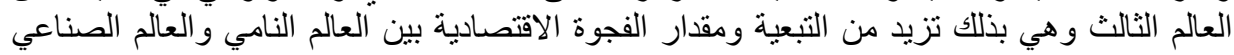

دـ النظرية التتموية: الإعلام التنموي وفق النظام الإعلامي الجديد

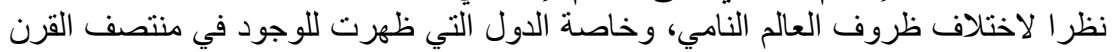

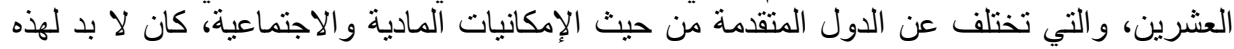

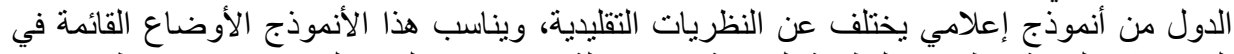

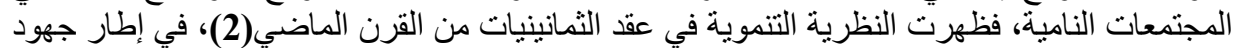

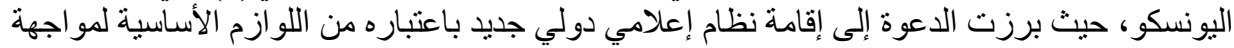

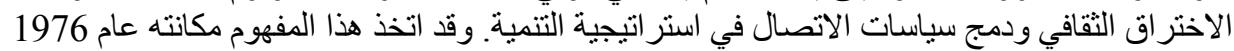

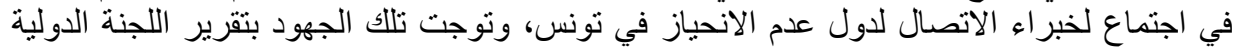

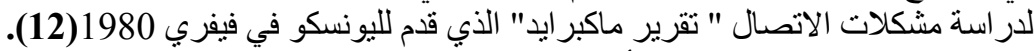

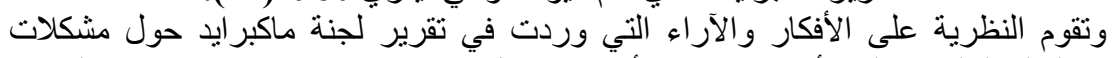

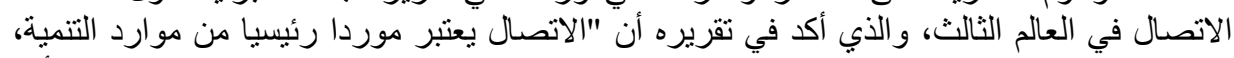

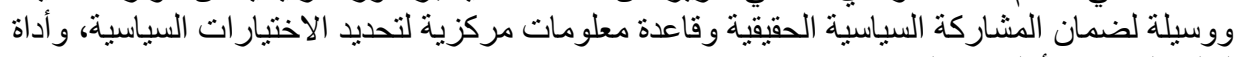

لخلق الوعي بالأولويات القومية" (5).

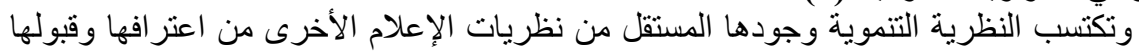

للتنمية الثاملة و التغيير الاجتماعي، وتتلخص التخد أفكار ها فيما يأتي(5):

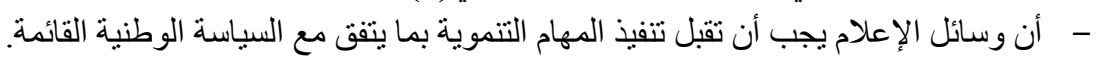

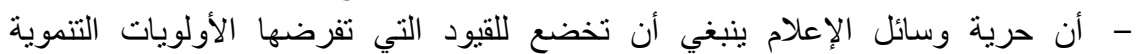
و الاحتياجات الاقتصادية للمجتمع.

- - يجب أن تعطى وسائل الإعلام أولوية للثقافة الوطنية و اللغة الوطنية في محتوى ما تقدمه.

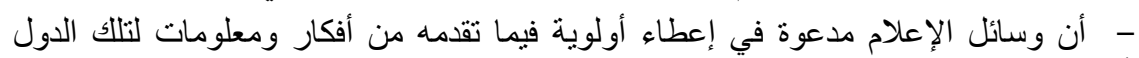
النامية الأخرى القريية جغر افيا وسياسيا وثقافيا.

- أن الصحفيين والإعلاميين في وسائل الإعلام لهم الحرية في جمع وتوزيع المعلومات

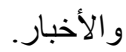


- - أن للاولة الحق في مر اقبة وتنفيذ أنشطة وسائل الإعلام واستخدام الرقابة خدمة للأهداف

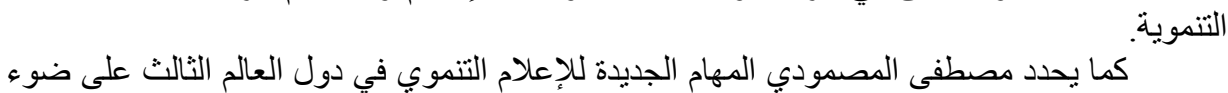
مفهوم النظام الإعلامي الجديد في النقاط الآتية (18): -ضرورة الارتباط بأهداف التتمية الثناملة وخططها، وضرورة التكامل بين السياسات الثقافية

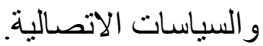

ـ ـ تدعيم الانتماء القومي و الرغبة في المشاركة السياسية، وخلق الوعي لاى الجماهير بأهية الاكتفاء الذاتي و الاعتماد على النفس.

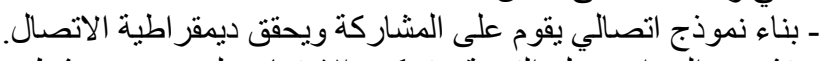

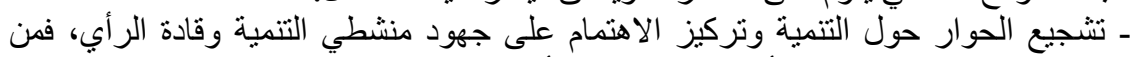
خلال هؤلاء تستطيع وسائل الإعلام التأثير على مجير مجرى الأحداث.

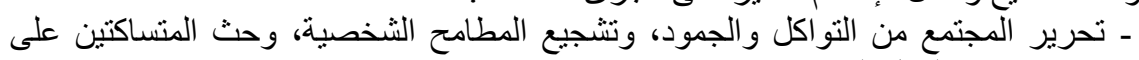
تحسين ظروف حياتهم بالعمل البناء. ـ تشخيص وتسجيل التحو لات الاقتصادية ورصد الاكتثافات الجديدة، وكثف الانعكاسات التي قد تكون عائقا في سبيل التنمية.

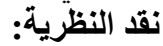

لم تسلم هذه النظرية أيضا من انتقادات المختصين رغم الأهداف التي سطرت من أجل تحقيقها،

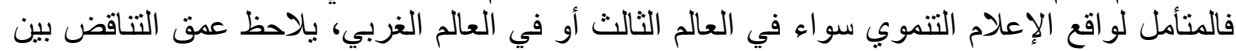

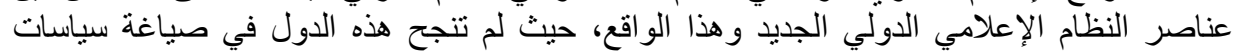

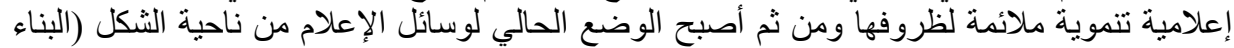

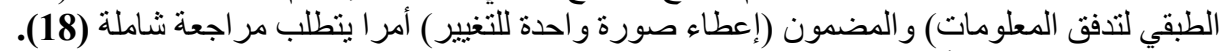

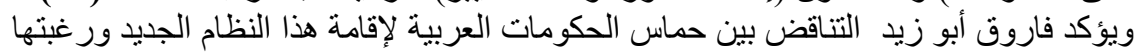

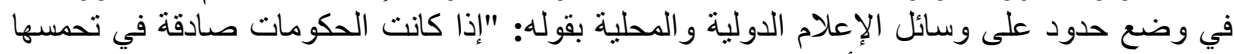

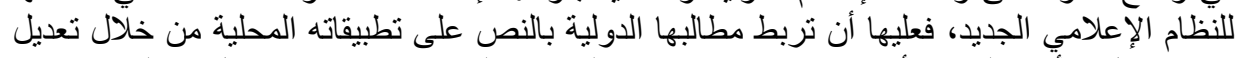

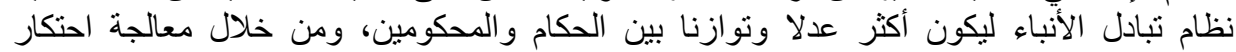

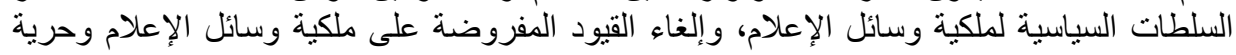

إصدار الصحف" (10).

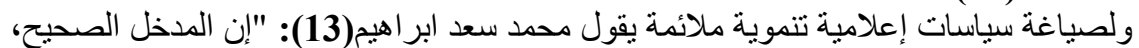

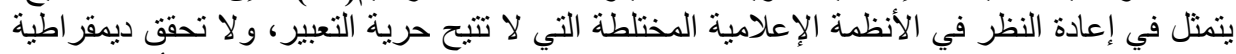

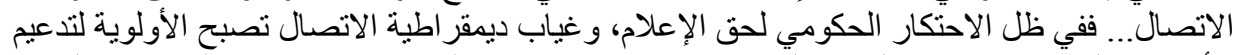

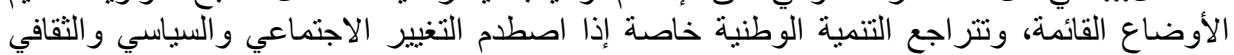
بمصالح السلطات السياسية الحاكمة". ومن خلال استعراض نظريات الإعلام التتموي في دول العالم الثالث يمكن أن نوجز

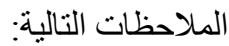

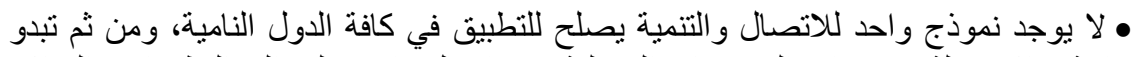

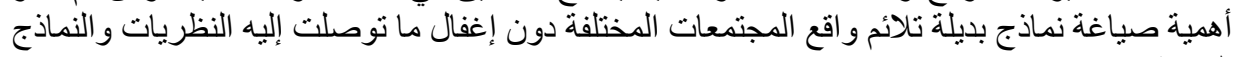

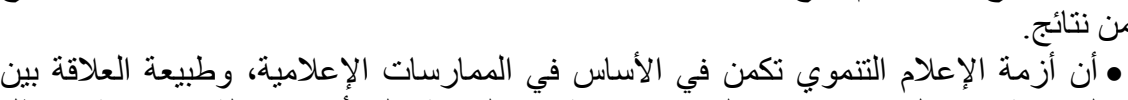

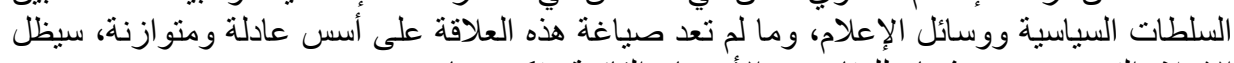

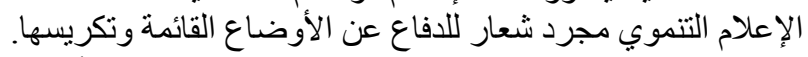

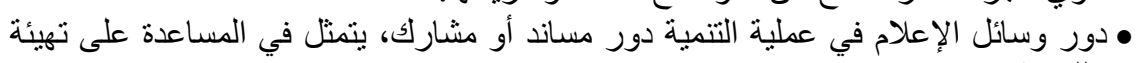

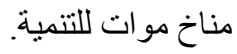




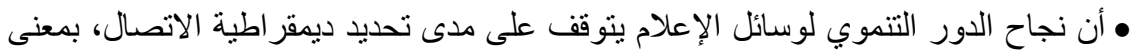

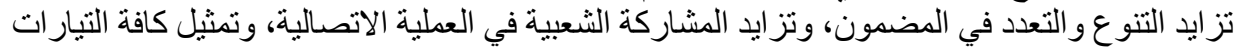
و القوى الاجتماعية و السياسية في وسائل الإعلام كما وكيفا.

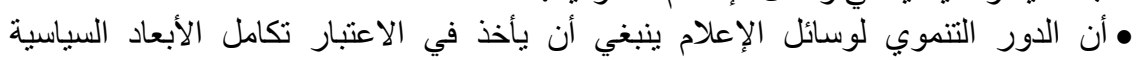

و الاقتصادية والاجتماعية و الثقافية لعملية التنمية (13).

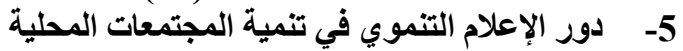

يقصد بتتمية المجتمعات المحلية في الدول النيامية التئية التباع الأساليب الحديثة في العمل الاجتماعي

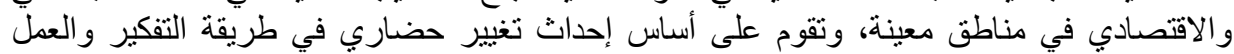

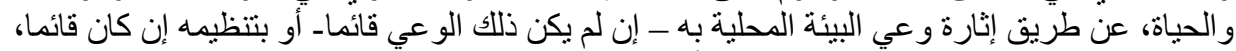
ثم بالمشاركة في الإعداد و التنفيذ من جانب أعضاء البئية البئة المحلية جميعا في المستويات الميات المككنة عمليا

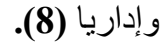

ويمكن الحديث عن دور الإعلام التنموي في التتمية المحلية من خلال الأبعاد الآتية:

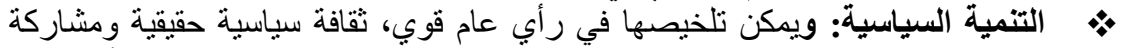

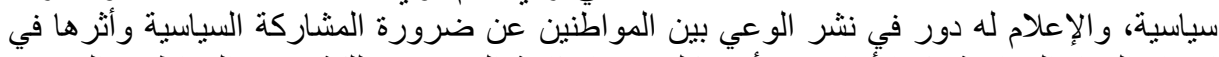

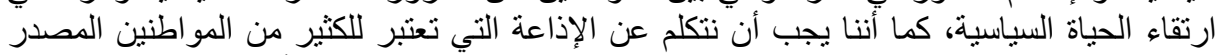

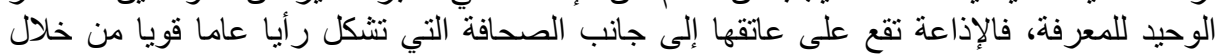

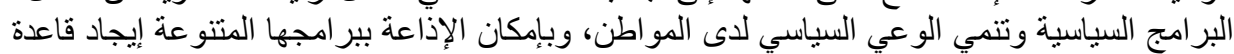

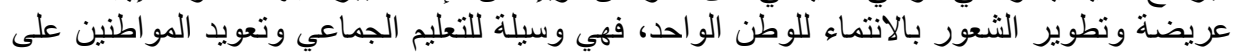

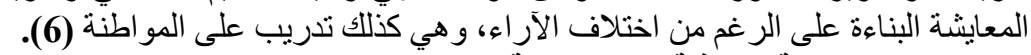

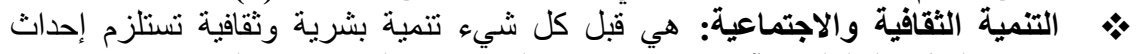

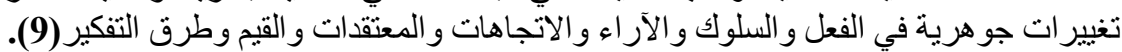

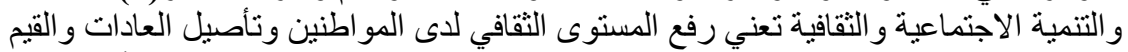

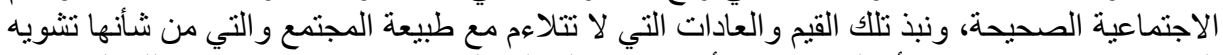

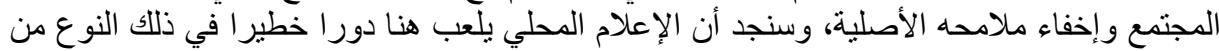

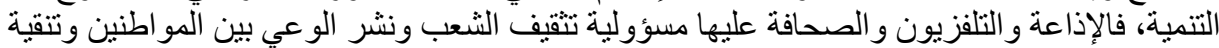

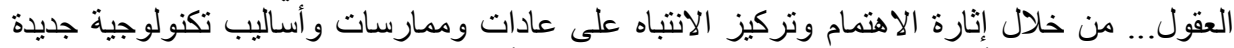

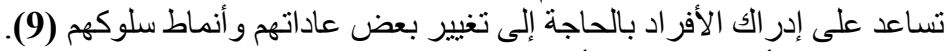

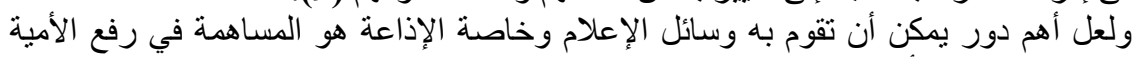

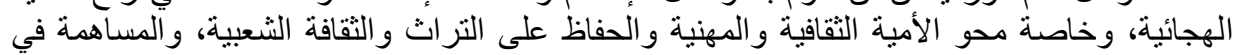

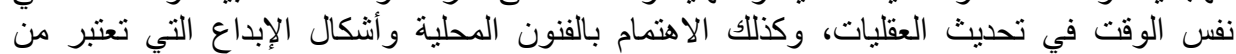

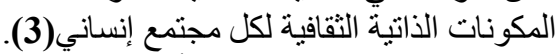

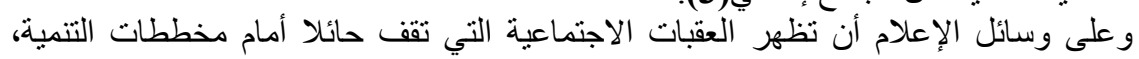

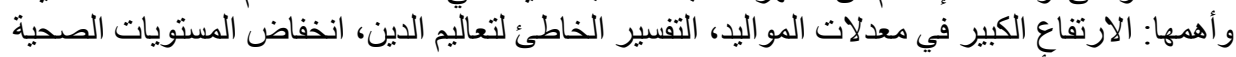
وارتفاع نسبة الأميين وتلوثئ البيئة...

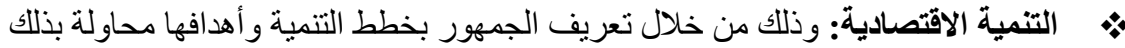

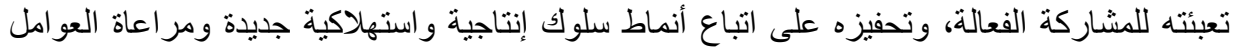

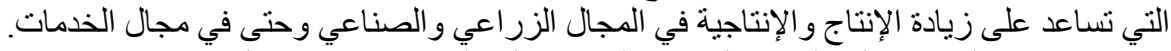

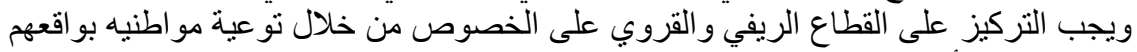

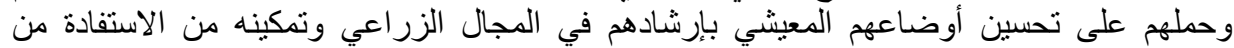

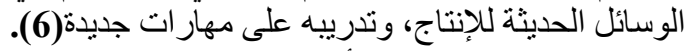

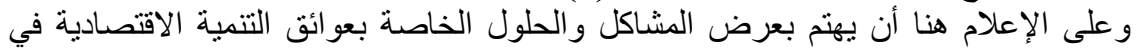

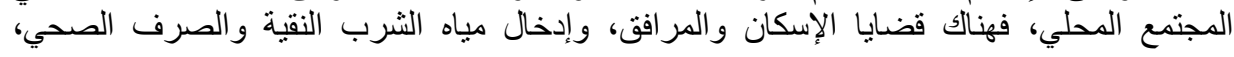


ومشاكل الزر اعة، وكل ما يهم الفلاح من معلومات و إرشادات عن البذور المنتقاة، والأسمدة الكيماوية

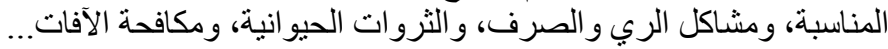

6- الأسس العلمية لاختيار الوسيلة المناسبة للإعلام التنموي:

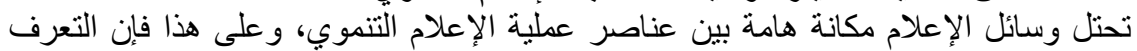

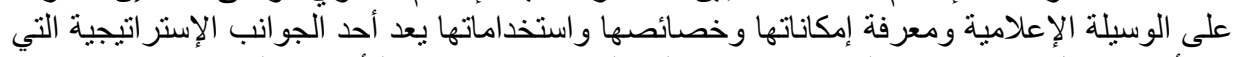

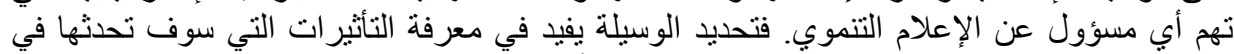

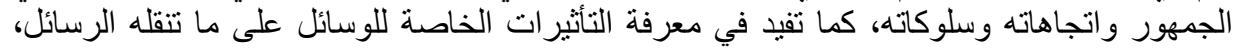
حيث تختلف طبيعة المعالجة للرسائل باختلاف الوبل الوسيلة المستخدمة.

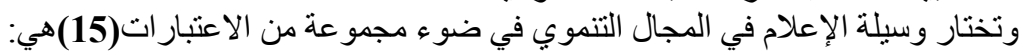

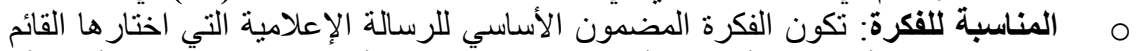

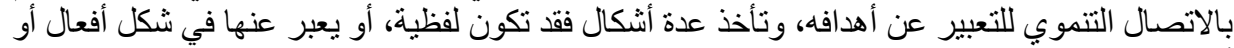

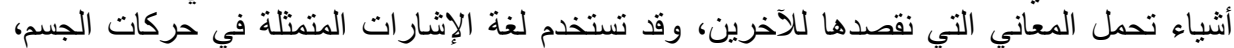
والألوان للتعبير عن المشاركة الوجدانية للآخرين، وقد يستخدم أكثر من شكل للتعبير عن الفكرة أو أو التئ

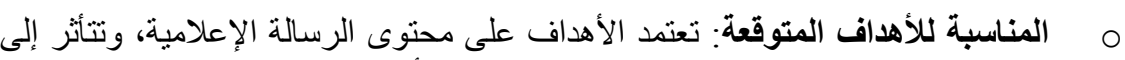

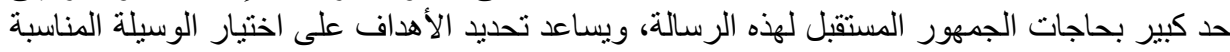

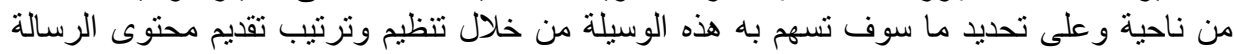
لتحقيق الهدف المحدد.

م قدرة الوسيلة على إثباع احتياجات الجمهور: يعد الجمهور عنصرا أساسيا للتخطيط

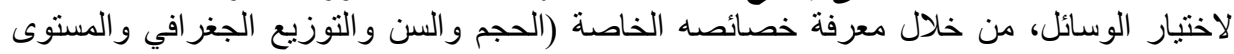

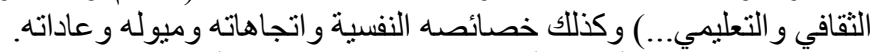

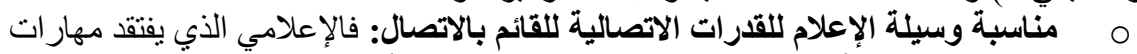

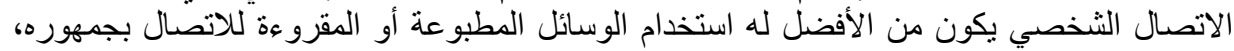

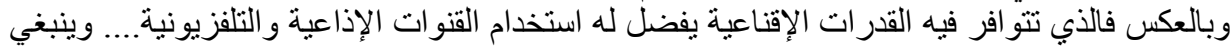

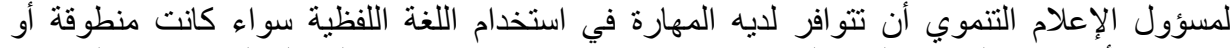

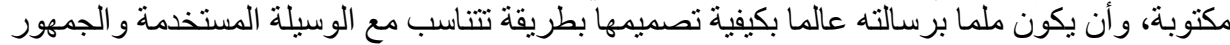
المستقبل لها وذلك ليتمكن من استخدام الوسائل المناسبة استخداما فعالا.

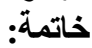

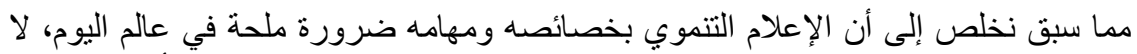

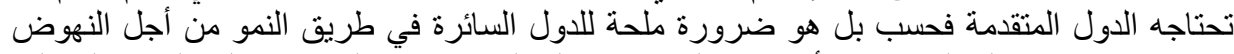

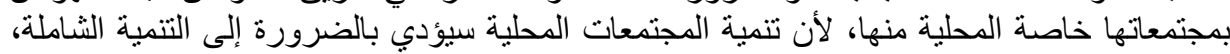

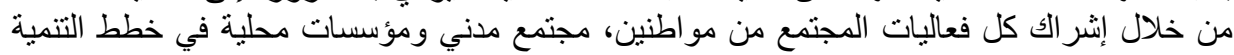

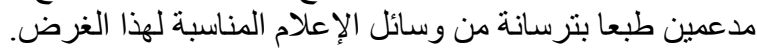
المراجع المئر

1. إسماعيل قيرة، علي غربي، سوسيولوجية التتمية، ديوان المطبوعات الجامعية، الجزائر، 2001

2. سعاد جبر سعيد، سيكولوجية الاتصال الجماهيري، عالم الكتب الحديث، الاردن، ط 1 1، 2008.

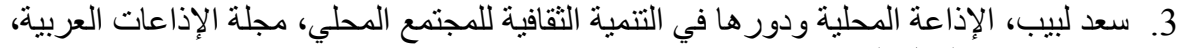
إتحاد إذاعات الدول العربية بتونس، 1985.

4. شاهيناز طلعت، وسائل الإعلام والتتمية الاجتماعية، 1980. 
5. شون ماكبر ايد وآخرون، أصوات متعددة وعالم واحد: الاتصال والمجتمع اليوم وغدا "تقرير

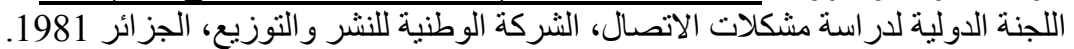

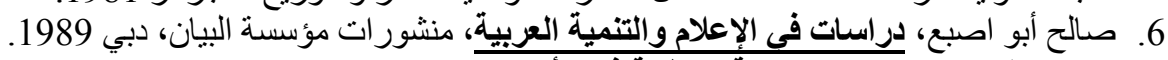

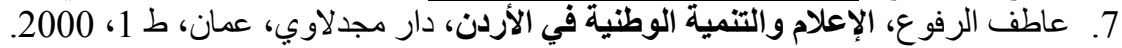

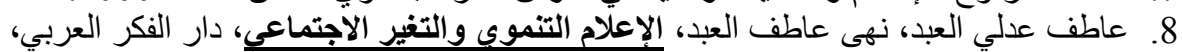

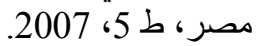

9. عو اطف عبد الرحمن، إثكالية الإعلام التنموي في الوطن العربي، دار الفكر العربي، القاهرة، د.ت.

10.فاروق أبو زيد، التحديات الإعلامية العربية: مقارنة بين عقدي الخمسينيات والثمانينيات،

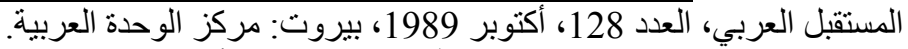

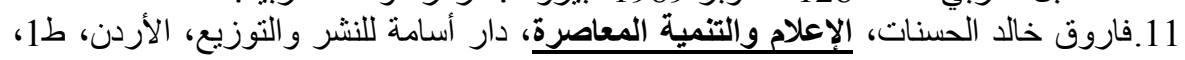
2011

12.فرنسيس بال، وسائل الإعلام والدول النامية، ترجمة حسين العودات، سلسلة در اسات إعلامية،

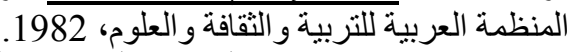

13.محمد سعد ابر اهيم: الصحافة والتنمية السياسية، دار الكتب العلمية للنشر والتوزيع، القاهرة، 1998

14.محمد سيد محمد، الإعلام والتنمية، دار المعارف، القاهرة، 1998 الإعلة 1979.

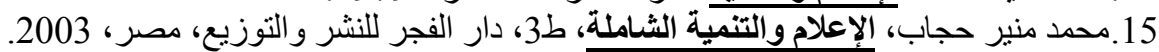

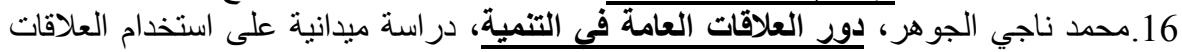

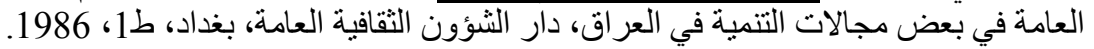

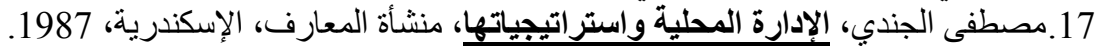

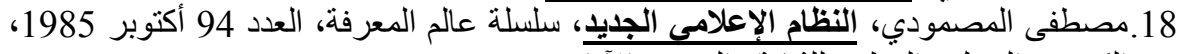

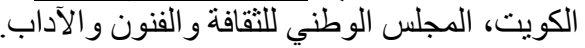

19. Wilbur Schramm, Mass Media and national development, Standford University Press, 1964.

تتناول هذه الورقة مفهوم الإعلام التتموي ودوره في تحقيق وتفعيل التنمية المحلية بصفتها بوابة

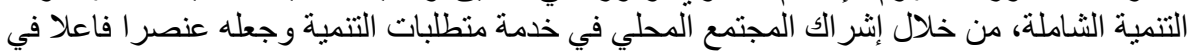

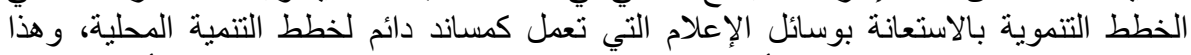

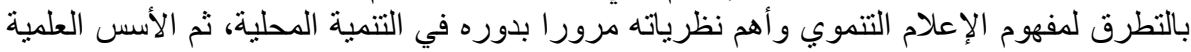

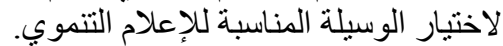

الكلمات المفتاحية: الإعلام، التنمية، الإعلام التتموي، التنمية المحلية. 